\title{
Upgrade of Biomass-Derived Levulinic Acid via Ru/C-Catalyzed Hydrogenation to $\gamma$-Valerolactone in Aqueous-Organic-Ionic Liquids Multiphase Systems
}

\author{
Maurizio Selva,* Marina Gottardo, and Alvise Perosa* \\ Department of Molecular Sciences and Nanosystems, Centre for Sustainable Technologies, Università Ca' Foscari Venezia, \\ Dorsoduro 2137, 30123 Venezia, Italy
}

\section{Supporting Information}

ABSTRACT: A liquid triphase system made by an aqueous phase, an organic phase, and an ionic liquid was designed and applied to the catalytic hydrogenation/dehydration of biomass-derived levulinic acid to $\gamma$-valerolactone. This paper demonstrates that, by operating at $100-150$ ${ }^{\circ} \mathrm{C}$ and $35 \mathrm{~atm}$ of $\mathrm{H}_{2}$, both in the presence of $\mathrm{Ru} / \mathrm{C}$ or of a homogeneous $\mathrm{Ru}$ precursor, the use of the triphase system designed to match the investigated reaction allows the following: (1) to obtain up to quantitative conversions and $100 \%$ selectivity toward the desired product; (2) to recover the product by simple phase separation; and (3) to preserve the catalyst activity for in situ recycles without loss of metal. Globally the investigated reaction proves the concept that a cradle-to-grave approach

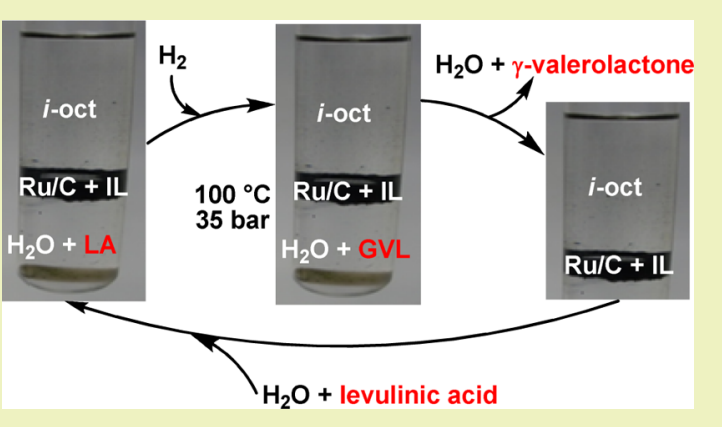
to the design of a catalytic reaction system can improve the global sustainability of a chemical transformation by improving efficiency, product isolation, and catalyst recycle.

KEYWORDS: Aqueous/organic multiphase, Catalyst segregation, Ru-nanoparticles, Recycle, Onium salts

\section{INTRODUCTION}

Levulinic acid (LA) has been classified among the 12 most attractive platform chemicals that can be produced from woodbased feedstock. ${ }^{1}$ LA can be efficiently synthesized through multiple acid-catalyzed reactions of 6- and 5-carbon monosaccharides that derive from different biomass sources, mostly cellulose wastes, such as paper mill sludge, urban waste paper, agricultural residues, and cellulose fines of papermaking. ${ }^{2-4}$ Available technologies for this process make it truly costeffective on a large scale (ton/day): ${ }^{5}$ accordingly, recent estimations indicate that LA can be produced at the price of 0.09-0.22 USD $/ \mathrm{kg}^{6}{ }^{6}$ This aspect and an intriguing chemical reactivity represent major drivers to the exploitation of LA as a renewable C5-source. Scheme 1 summarizes some of the potential routes for LA transformation. ${ }^{7}$

A plethora of different value-added products including fuel additives, monomers for plastics and textiles, and chemicals can be obtained from LA, in most cases by reductive transformations to lower the oxygen content of the molecule. ${ }^{7,8}$ Among them, hydrogenation of LA to $\gamma$-valerolactone (GVL) (Scheme 2) has recently gained special attention. The latter compound, in fact, if originated from biomass, can be considered as an archetype sustainable liquid for the production of both energy and carbon-based chemicals, including solvents, intermediates, and food additives. ${ }^{9-15}$

The catalytic hydrogenation of LA has been known for a long time. ${ }^{16-20}$ However, only recent systematic investigations have demonstrated that the selective conversion of LA to GVL is
Scheme 1. Derivatives of Levulinic Acid (LA) ${ }^{1}$

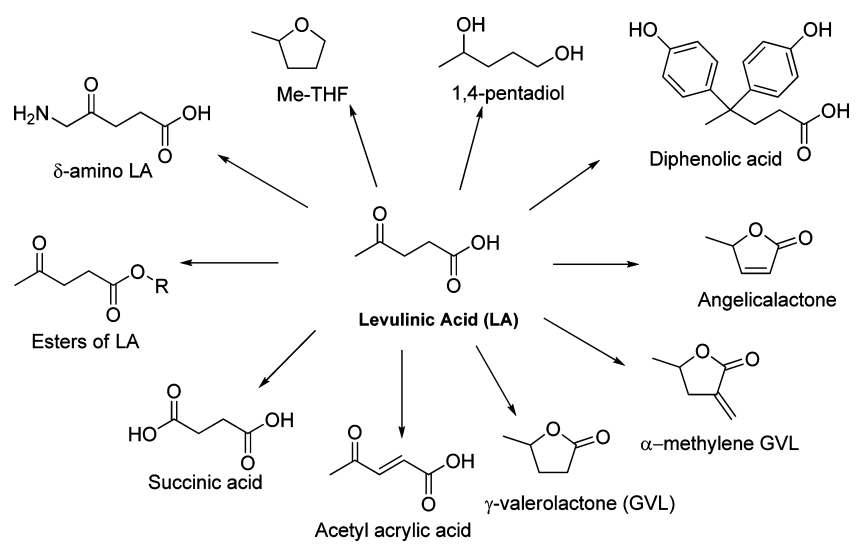

Scheme 2. Hydrogenation/dehydration of LA to GVL

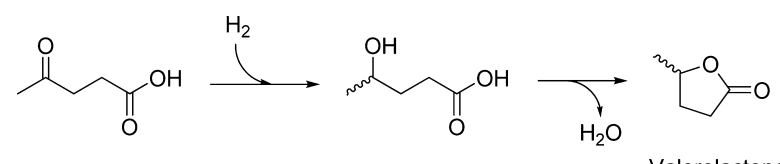

Levulinic Acid

$\gamma$-Hydroxyvaleric acid

$\gamma$-Valerolactone (GVL) 
most efficiently carried out on Ru-based catalysts, as either heterogeneous C-supported solids ${ }^{9,21-23}$ or homogeneous complexes. ${ }^{11-13,24,25}$ Procedures for the use of these catalytic systems as such, or in combination with cocatalysts or ligands, have been optimized to the point that excellent yields of GVL are achieved also by hydrogenating LA in aqueous solutions. This is crucial for bioderived LA, which is often available in aqueous feed. Intensification of the process for the hydrogenation of LA has been achieved by using the crude aqueous LA-formic acid mixture-coproduced directly from the acidic carbohydrate dehydration step-as feedstock. , $^{91-13,21-25}$ Under these conditions, formic acid could be used as a $\mathrm{H}_{2}$ donor for the reduction of LA. Further improvement of the sustainability of the process has involved optimization of catalyst support, acid cocatalyst selection, and milder experimental conditions. ${ }^{26}$ This investigation also addressed catalyst recycling through filtration and reuse. Despite the value of such methods, practical recovery and recycle of the (precious) metal catalyst is still an open problem particularly due to the reported loss of activity of the recovered catalytic systems and due to the difficulty in recycling water-based matrices. This largely unexplored issue is, however, crucial in view of practical applications of any of these catalytic hydrogenation methods and can be addressed by using liquid multiphase systems based on ionic liquids (ILs). It is known that ILs can form biphasic systems with organic species and have the ability to retain catalytic metal species. ${ }^{27-30}$ The main advantages are that the catalysts reside in a different liquid phase with respect to the reagents and products, making for easy recovery by phase separation, and that the metal catalyst is often stabilized by the IL. In addition, catalyst efficiency can sometimes be tuned by choosing the appropriate IL phase to immobilize the catalyst. A number of such multiphase systems (homogeneous as well as heterogeneous) have been reviewed. ${ }^{30,31,30,32}$

The present work is based on our long-standing experience of the engineering of multiphase systems composed of an organic solvent, water, and an IL, for cleaner catalytic procedures and (precious) catalyst recovery. ${ }^{30,32,33}$ Under such (multiphase) conditions, phase separation and catalyst segregation are often made possible by common ionic liquids, including ammonium or phosphonium quaternary salts. For example, trioctylmethylammonium chloride $\left[\mathrm{N}_{8,8,8,1}\right][\mathrm{Cl}]$ was used previously for the formation of catalytic $\mathrm{Pd}$ nanoparticles and allowed easy product-catalyst separation as well as straightforward catalyst recycle, thanks to built-in separation. ${ }^{34}$ Another triphasic organic/aqueous/IL (again with $\left[\mathrm{N}_{8,8,8,1}\right][\mathrm{Cl}]$ ) system was used by us for the hydroformylation reaction. ${ }^{33}$ In this case also, simple recovery and recycle of the catalytic system for repeated runs was possible, without detectable loss of activity, and without any leaching of metal to the organic phase.

This paper describes an original design of multiphase systems whereby, through the choice of readily available phosphonium salts as ILs, an efficient hydrogenation/dehydration of LA to $\gamma$ valerolactone can be carried out in aqueous solutions in the presence of either a heterogeneous supported $\mathrm{Ru}$ catalyst or a homogeneous $\mathrm{Ru}$ precursor. Under such conditions, the major advantage is the perfect confinement of the catalytic system in the IL phase that allows not only an easy isolation of the product in quantitative yields but also an in situ reuse of catalysts for at least eight recycles with unchanged performances.

\section{EXPERIMENTAL SECTION}

Materials and Chemicals. All chemicals are reagent-grade and used without further purification. Levulinic acid, formic acid, and $\mathrm{RuCl}_{3} \cdot \mathrm{H}_{2} \mathrm{O}$ were purchased from Sigma-Adrich. $\mathrm{Ru} / \mathrm{C} 5$ wt \% was from BASF. Deionized water was used in all experiments. $\mathrm{H}_{2}$ gas was purchased from SIAD. All ionic liquids $\left(\left[\mathrm{N}_{8,8,8,1}\right] \mathrm{Cl},\left[\mathrm{P}_{8,8,8,1}\right]\left[\mathrm{NTf}_{2}\right]\right.$, $\left.\left[\mathrm{N}_{8,8,8,1}\right]\left[\mathrm{NTf}_{2}\right],\left[\mathrm{N}_{8,8,8,1}\right][\mathrm{TFA}],\left[\mathrm{P}_{8,8,8,1}\right] \mathrm{NO}_{3}\right)$ were synthesized by a published procedure. ${ }^{3}$

Monitoring Reaction Progress and Characterization of Catalysts. The conversion and selectivity of hydrogenation reactions of levulinic acid were determined by ${ }^{1} \mathrm{H}$ NMR on a Varian Unity $400 \mathrm{MHz}$ NMR spectrometer. The structure of $\mathrm{Ru}$ catalyst after the reaction in the multiphase system using $\left[\mathrm{N}_{8,8,8,1}\right] \mathrm{Cl}$ was examined by transmission electron microscopy (TEM). TEM measurements were performed using a JEM 3010 (JEOL) electron microscope operating at $300 \mathrm{kV}$; the lens parameters were $\mathrm{Cs}=0.6 \mathrm{~mm}, \mathrm{Cc}=1.3 \mathrm{~mm}$, giving a point resolution of $0.17 \mathrm{~nm}$ at Scherzer defocus. TEM samples were prepared by sonicating a drop of the ionic liquid phase containing the catalyst for $5 \mathrm{~min}$ in order to disrupt possible agglomerates, transferring a $5 \mu \mathrm{L}$ droplet of suspension onto an amorphous carbon film, coating a 200 mesh copper grid, drying at room temperature, and then placing into the microscope.

Typical Experimental Procedure for the Triphasic Hydrogenation Catalyzed by 5 wt \% Ru/C. To a glass tube containing $\mathrm{Ru} / \mathrm{C}(25 \mathrm{mg})$ and $\left[\mathrm{P}_{8,8,8,1}\right]\left[\mathrm{NTf}_{2}\right](0.9-1.0 \mathrm{mmol})$, $\mathrm{H}_{2} \mathrm{O}(4.4 \mathrm{~mL})$ and isooctane $(4.4 \mathrm{~mL})$ were added and stirred until complete dissolution of the catalyst in the IL phase. Levulinic acid $(810 \mu \mathrm{L}, 7.875 \mathrm{mmol})$ was then added to the system. The tube was placed into a $250 \mathrm{~mL}$ stainless steel autoclave, pressurized to 35 atm with $\mathrm{H}_{2}$, and heated at due temperature for the due time with vigorous stirring (details on temperatures/times are given in the Results section). The reactor was then cooled to room temperature, and the residual gases were vented. At the end of the reaction, the catalyst was still completely segregated in the IL phase. The water phase was separated and extracted with $\mathrm{CDCl}_{3}$. Reagent conversion and product distribution were determined by ${ }^{1} \mathrm{H}$ NMR integration.

Typical Experimental Procedure for the Triphasic Hydrogenation using $\mathrm{RuCl}_{3} \cdot \mathrm{H}_{2} \mathrm{O}$. To a glass tube containing $\mathrm{RuCl}_{3} \cdot \mathrm{H}_{2} \mathrm{O}(20 \mathrm{mg})$ and $\left[\mathrm{N}_{8,8,8,1}\right][\mathrm{Cl}](0.9-1.0 \mathrm{mmol}), \mathrm{H}_{2} \mathrm{O}$ $(4.4 \mathrm{~mL})$ and isooctane $(4.4 \mathrm{~mL})$ were added with stirring. The catalyst was completely dissolved in the water phase. Levulinic acid $(810 \mu \mathrm{L}, 7.875 \mathrm{mmol})$ was then added to the system. The tube was placed into a $250 \mathrm{~mL}$ stainless steel autoclave, pressurized to $35 \mathrm{~atm}$ with $\mathrm{H}_{2}$, and heated at $150{ }^{\circ} \mathrm{C}$ for $16 \mathrm{~h}$, with vigorous stirring. The reactor was then cooled to room temperature, and the residual gases were vented. At the end of the reaction, the catalyst was completely segregated in the IL phase. The water phase was separated and extracted with $\mathrm{CDCl}_{3}$. Reagent conversion and product distribution were determined by ${ }^{1} \mathrm{H}$ NMR integration.

Typical Experimental Procedure for the Triphasic Hydrogenation of the Levulinic Acid/Formic Acid Mixture with 5 wt \% Ru/C. To a glass tube containing $\mathrm{Ru} / \mathrm{C}(25 \mathrm{mg})$ and $\left[\mathrm{P}_{8,8,8,1}\right]\left[\mathrm{NTf}_{2}\right](0.9-1.0 \mathrm{mmol}), \mathrm{H}_{2} \mathrm{O}(4.4$ $\mathrm{mL})$ and isooctane $(4.4 \mathrm{~mL})$ were added and stirred until complete dissolution of the catalyst in IL phase. Levulinic acid $(810 \mu \mathrm{L}, 7.875 \mathrm{mmol})$ and formic acid $(300 \mu \mathrm{L}, 7.875 \mathrm{mmol})$ were then added to the system. The tube was placed into a 250 $\mathrm{mL}$ stainless steel autoclave. Subsequently, the autoclave was flushed several times with nitrogen to remove air, pressurized to the desired reaction pressure (typically $35 \mathrm{~atm} \mathrm{H}_{2}$ ), and heated 
at $150{ }^{\circ} \mathrm{C}$ for the due time (typically for $16 \mathrm{~h}$ ), with vigorous stirring. The reactor was then cooled to room temperature, and the residual gases were vented. The water phase was separated and extracted with $\mathrm{CDCl}_{3}$. Reagent conversion and product distribution were determined by ${ }^{1} \mathrm{H}$ NMR integration. The same procedure was used for reactions run in the presence of $\mathrm{RuCl}_{3} \cdot \mathrm{H}_{2} \mathrm{O}(20 \mathrm{mg})$ and $\left[\mathrm{N}_{8,8,8,1}\right] \mathrm{Cl}(0.9-1.0 \mathrm{mmol})$.

\section{RESULTS}

Setup of the Multiphase System. The IL $\left[\mathrm{N}_{8,8,8,1}\right][\mathrm{Cl}]$ IL1 bearing a lipophilic cation was synthesized following a procedure previously described by us. ${ }^{35}$ In the first instance a heterogeneous catalyst was considered, and in particular the one of choice for these reactions was identified as $\mathrm{Ru} / \mathrm{C}$, based on literature reports. ${ }^{9,36}$ In view of obtaining a multiphase system with three separate organic-IL-water (liquid) phases, the organic solvent was at first chosen for its immiscibility with water, coupled with its ability to dissolve the substrate LA and the product GVL.

Six different organic solvents were selected based on their availability, low cost, and acceptable toxicological profiles (Table 1). Apolar isooctane and cyclohexane, which are

Table 1. Solubility Properties of Solvents Tested for the Triphase System

\begin{tabular}{lccc}
\multicolumn{1}{c}{ solvent } & LA solubility & GVL solubility & solubility in water at $20{ }^{\circ} \mathrm{C}$ \\
isooctane & no & no & immiscible \\
cyclohexane & no & no & immiscible \\
toluene & yes & yes & $0.52 \mathrm{~g} / \mathrm{L}$ \\
ethyl acetate & yes & yes & $0.83 \mathrm{~g} / \mathrm{L}$ \\
ethyl lactate & yes & yes & miscible \\
acetonitrile & yes & yes & miscible \\
water & yes & yes & miscible \\
\hline
\end{tabular}

immiscible with water, were not able, however, to dissolve the substrate or the product. At the other extreme, polar ethyl lactate and acetonitrile both dissolved the reactant and the product but were also soluble with water, preventing formation of a triphase system. Toluene satisfied both requirements but was ruled out because in a test reaction it was hydrogenated to methylcyclohexane. Ethyl acetate (EA) was finally selected.

We then went about investigating the catalytic hydrogenation of LA under multiphase conditions. On the basis of our experience on the design of multiphase systems where heterogeneous $\mathrm{C}$-supported catalysts are preferentially sequestered in an IL phase, ${ }^{32,34}$ and based on available data comparing the performance of different supported metals for the investigated reaction, our choice fell on $5 \% \mathrm{Ru} / \mathrm{C}$, which was among the most active and selective systems. ${ }^{9}$ The hydrogenation of LA catalyzed by commercial $5 \% \mathrm{Ru} / \mathrm{C}(0.15 \mathrm{~mol} \%$, $0.0124 \mathrm{mmol}$ of $\mathrm{Ru})^{36}$ was then conducted for $4 \mathrm{~h}$ at $100{ }^{\circ} \mathrm{C}$ and $35 \mathrm{~atm}$ of $\mathrm{H}_{2}$, in a multiphase system that comprised EA $(4.4 \mathrm{~mL})$, water $(4.4 \mathrm{~mL}), \mathrm{LA}(810 \mu \mathrm{L})$, and variable amounts of $\left[\mathrm{N}_{8,8,8,1}\right][\mathrm{Cl}]$ (up to $884 \mathrm{mg}$ ). The choice of 35 atm as operating pressure was dictated both by a set of exploratory experiments conducted between 20 and 50 atm (here not described) and by precedents in the literature. ${ }^{7,9}$ The results are summarized in Table 2.

In the absence of IL (run 1), the reaction was extremely efficient, while increasing amounts of $\left[\mathrm{N}_{8,8,8,1}\right][\mathrm{Cl}]$ seemed to depress the conversion and yield (runs 2 and 3 ). In all cases, however, GVL was partitioned between EA and water in a 3 to
Table 2. Conversion of LA to GVL in an EA/Water/ $\left[\mathbf{N}_{8,8,8,1}\right][\mathrm{Cl}]$ Triphase System ${ }^{a}$

\begin{tabular}{ccc}
{$\left[\mathrm{N}_{8,8,8,1}\right][\mathrm{Cl}] / \mathrm{Cat}[\mathrm{wt} / \mathrm{wt}]$} & $\mathrm{LA}$ conv. & $\mathrm{GVL}$ yield \\
5.7 & $100 \%$ & $91 \%^{b}$ \\
35.4 & $56 \%$ & $55 \%^{b}$ \\
$11 \%$ & $11 \%^{b}$ \\
${ }^{a}$ Conditions: $\mathrm{Ru} / \mathrm{C}(0.15 \mathrm{~mol} \%, 0.0124 \mathrm{mmol}$ of $\mathrm{Ru}), 100{ }^{\circ} \mathrm{C}, 35 \mathrm{~atm}$ \\
of $\mathrm{H}_{2}, 4$ h. ${ }^{b} \mathrm{GVL}$ partitioned between EA and $\mathrm{H}_{2} \mathrm{O}: 3 / 1$ ratio. \\
\hline
\end{tabular}

1 ratio, making quantitative recovery of the product virtually impossible.

We therefore returned to the drawing board and set our first priority as obtaining good phase separation. To this end we selected a multiphase system composed of an aqueous solution of levulinic acid (1.8 M; $4.4 \mathrm{~mL}$ ), isooctane (i-oct, $4.4 \mathrm{~mL}), 5 \%$ $\mathrm{Ru} / \mathrm{C}(25 \mathrm{mg}, 0.0124 \mathrm{mmol}$ of $\mathrm{Ru})$, and different amounts of $\left[\mathrm{N}_{8,8,8,1}\right][\mathrm{Cl}](33-315 \mathrm{mg})$ as a third liquid phase. The mixture was placed in a test tube, vigorously stirred for $1 \mathrm{~h}$ at room temperature (rt), and allowed to stand. Regardless of the amount of $\left[\mathrm{N}_{8,8,8,1}\right][\mathrm{Cl}]$ used, the IL always appeared as a separate liquid phase between the top organic and the bottom aqueous phases, giving neat phase separation; the heterogeneous $\mathrm{Ru} / \mathrm{C}$ catalyst remained segregated in the middle (IL) phase (Figure 1, right). By contrast, without the IL, $\mathrm{Ru} / \mathrm{C}$ was dispersed among the phases (Figure 1, left).

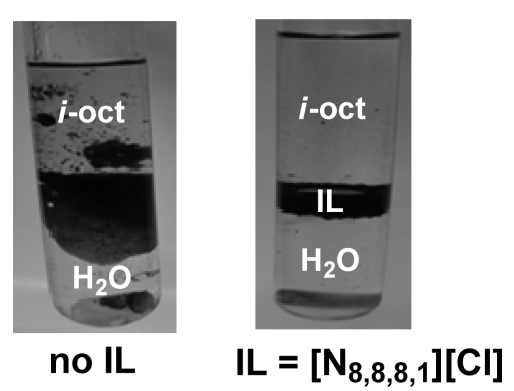

Figure 1. Pictures of aqueous solutions of levulinic acid (1.8 M; 4.4 $\mathrm{mL})$, isooctane $(4.4 \mathrm{~mL}), 5 \% \mathrm{Ru} / \mathrm{C}(25 \mathrm{mg}, 0.0124 \mathrm{mmol}$ of $\mathrm{Ru})$ : without IL (left) and with $\left[\mathrm{N}_{8,8,8,1}\right][\mathrm{Cl}](138 \mathrm{mg}, 0.34 \mathrm{mmol})$ (right).

We named this setup "inverse" multiphase system because, contrarily to all multiphase arrangements previously used by us, the organic reactant LA and product GVL, both highly polar compounds, remained dissolved in the aqueous phase. It should be noted that, while $i$-oct had no apparent role as a solvent for the chemical species, it was necessary, however, to obtain good phase separation and catalyst segregation, as well as for the efficiency of the reaction.

Inverse Multiphase hydrogenations of LA in the presence of $\mathrm{Ru} / \mathrm{C}$. Amount of IL. With the aim of establishing the optimal composition of the multiphase system, we started by determining the optimal quantity of IL. Accordingly a series of hydrogenation reactions were run at $100{ }^{\circ} \mathrm{C}$, at 35 atm of $\mathrm{H}_{2}$, and for $4 \mathrm{~h}$, by progressively increasing the amounts of $\left[\mathrm{N}_{8,8,8,1}\right][\mathrm{Cl}]$ (from 35 to $315 \mathrm{mg} ; 0.087-0.78 \mathrm{mmol}$ ) in the triphase system of Figure 1 (right). All other conditions $(\mathrm{Ru} / \mathrm{C}$, volumes and concentrations of both aqueous and $i$-octane phases) remained equal. The results are summarized in Figure 2.

In the presence of the IL, a third liquid phase between the aqueous and hydrocarbon solvents was observed both at the start and at the end of the hydrogenation tests. In this (third) 




Figure 2. Conversion of LA to GVL as a function of the amount of IL in the $i$-octane-water- $\left[\mathrm{N}_{8,8,8,1}\right][\mathrm{Cl}]$ triphase system with $5 \% \mathrm{Ru} / \mathrm{C}$ after $4 \mathrm{~h}$. Conditions: $100{ }^{\circ} \mathrm{C}, p\left[\mathrm{H}_{2}\right]=35$ bar, $\mathrm{Ru} 0.15 \mathrm{~mol} \%$ (0.0124 mmol of $\mathrm{Ru})$, water $=i$-octane $=4.4 \mathrm{~mL},\left[\mathrm{~N}_{8,8,8,1}\right][\mathrm{Cl}]=35-316 \mathrm{mg}$.

phase, the $\mathrm{Ru} / \mathrm{C}$ catalyst was always perfectly confined. The profile of Figure 2 indicates that an optimal amount of IL could be found to favor the LA conversion: in particular, this increased up to $60-65 \%$ when the IL/Cat $(\mathrm{w} / \mathrm{w})$ ratio was in the interval between 3 and 6 . In all cases, the reaction proceeded with the exclusive formation of GVL.

Best IL. Although the $\left[\mathrm{N}_{8,8,8,1}\right][\mathrm{Cl}]$ IL did form three separate phases, it was partially soluble, however, in the aqueous phase as well. NMR analyses showed that some 2-3\% of $\left[\mathrm{N}_{8,8,8,1}\right][\mathrm{Cl}]$ (by weight) was lost in water after each hydrogenation test. We therefore sought a less water-soluble IL by modifying the anion. To this end we prepared more lipophilic ILs such as $\left[\mathrm{N}_{8,8,8,1}\right] \mathrm{NTf}_{2}$ IL2 and $\left[\mathrm{P}_{8,8,8,1}\right] \mathrm{NTf}_{2}$ IL3. Also, two more salts with intermediate lipophilicity, $\left[\mathrm{N}_{8,8,8,1}\right]$ $\mathrm{CF}_{3} \mathrm{COO}$ IL4 and $\left[\mathrm{P}_{8,8,8,1}\right] \mathrm{NO}_{3}$ IL5, were considered. The hydrogenation of LA was then carried out under the conditions of Figure 2, in the presence of IL2-IL5 (IL/Cat =10, wt/wt). The results are listed in Table 3 .

Table 3. Conversion of LA to GVL in Different $i$-Octane/ Water/IL Triphase Systems ${ }^{a}$

\begin{tabular}{clcl}
$\mathrm{IL}^{b}[\mathrm{IL} / \mathrm{Cat}=10$, & $\begin{array}{c}\text { LA conversion } \\
\text { wt } / \mathrm{wt}]\end{array}$ & $\begin{array}{c}\text { solubility of IL in } \\
\mathrm{H}_{2} \mathrm{O}(\%, \mathrm{wt})\end{array}$ \\
\hline 1 & {$\left[\mathrm{~N}_{8,8,8,1}\right][\mathrm{Cl}]$, IL1 } & 32 & $2-3$ \\
2 & {$\left[\mathrm{~N}_{8,8,8,1}\right]\left[\mathrm{NTf}_{2}\right]$, IL2 } & 100 & not measurable \\
3 & {$\left[\mathrm{P}_{8,8,8,1}\right]\left[\mathrm{NTf}_{2}\right]$, IL3 } & 100 & not measurable \\
4 & {$\left[\mathrm{~N}_{8,8,8,1}\right][\mathrm{TFA}]$, IL4 } & 100 & 41 \\
5 & {$\left[\mathrm{P}_{8,8,8,1}\right] \mathrm{NO}_{3}$, IL5 } & 100 & 17
\end{tabular}

${ }^{a}$ Conditions: $\mathrm{Ru} / \mathrm{C}(0.15 \mathrm{~mol} \%, 0.0124 \mathrm{mmol}$ of $\mathrm{Ru}), 100{ }^{\circ} \mathrm{C}, 35 \mathrm{~atm}$ of $\mathrm{H}_{2}, 4$ h. ${ }^{b} 250 \mathrm{mg}$ of each IL were used: IL2 (0.38 mmol); IL3 (0.37 mmol); IL4 (0.50 mmol); IL5 (0.56 mmol).

Unlike the reaction with $\left[\mathrm{N}_{8,8,8,1}\right][\mathrm{Cl}]$ that reached $32 \%$ conversion, all the reactions with the four salts IL2-IL5 achieved complete conversion in $4 \mathrm{~h}$. The less lipophilic IL4 and IL5, however, were significantly soluble in water and therefore were abandoned. The triflamide ammonium and phosphonium IL2 and IL3 salts instead prompted 100\% conversion after $4 \mathrm{~h}$ without partitioning into the aqueous phase and with perfect segregation of $\mathrm{Ru} / \mathrm{C}$.

At the end of the reactions carried out in the presence of IL2 and IL3 (entries 2 and 3), the final aqueous solutions of GVL were carefully extracted with ethyl acetate, dried over $\mathrm{Na}_{2} \mathrm{SO}_{4}$, and filtered. After solvent removal under vacuum, crude GVL was isolated in quantitative (99\%) yields. This confirmed the accuracy of NMR analyses for the evaluation of conversion and selectivity as well as the overall reaction mass balance.

Another remarkable difference and advantage over the use of $\left[\mathrm{N}_{8,8,8,1}\right][\mathrm{Cl}]$ was that the reaction outcome was not affected by the amount of both triflamide salts IL2 and IL3. Further hydrogenation experiments-not shown here-showed that the LA conversion remained quantitative over $4 \mathrm{~h}$, in the whole range of IL/Cat ratio (wt/wt) between 0 and 25. IL2 and IL3 were therefore the most suitable ILs to set up our multiphase system. Because of the higher thermal stability of phosphonium versus ammonium salts, ${ }^{37}\left[\mathrm{P}_{8,8,8,1}\right]\left[\mathrm{NTf}_{2}\right]$ IL3 was chosen to proceed with the investigation.

In the presence of IL3, additional tests were then carried out to investigate the effect of the reaction time and of the optimal $\mathrm{IL} / \mathrm{Cat}$ ratio for quantitative $\mathrm{Ru} / \mathrm{C}$ confinement. Conditions for the temperature and volumes/concentrations of aqueous/ $i$ octane phases were those shown in Table 3.

Three sets of reactions were carried out at $0.5,1$, and $2 \mathrm{~h}$, respectively. Within each set, the IL3/Cat molar ratio ranged between 6 and 25 to 1 . The results are reported in Figure 3.

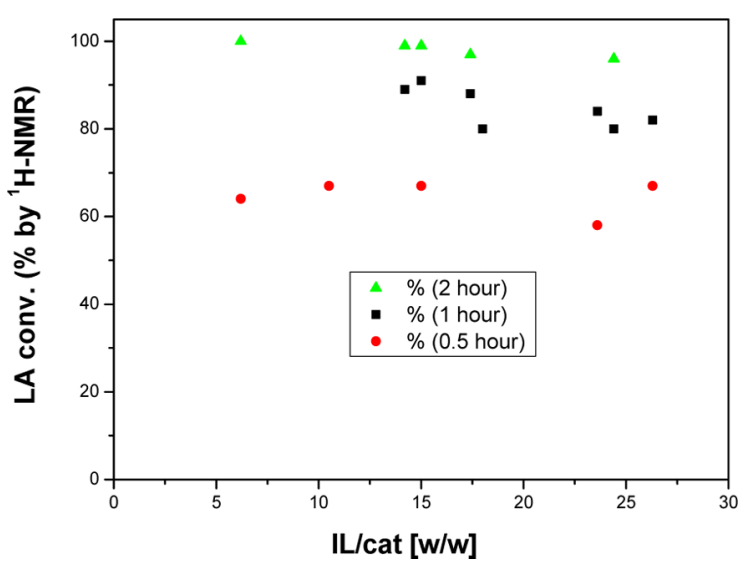

Figure 3. Conversion of LA to GVL with IL3 and $5 \% \mathrm{Ru} / \mathrm{C}$ as a function of the amount of IL after $0.5,1$, and $2 \mathrm{~h}$ (red, black, and green dots, respectively). Conditions: $100{ }^{\circ} \mathrm{C}, p\left[\mathrm{H}_{2}\right]=35$ bar, $\mathrm{Ru} 0.15 \mathrm{~mol}$ $\%$, water $=i$-oct $=4.4 \mathrm{~mL},\left[\mathrm{P}_{8,8,8,1}\right]\left[\mathrm{NTf}_{2}\right]=355-657 \mathrm{mg}=0.53-0.99$ mmol.

The screening demonstrated that the IL3 amount had little (if any) effect on the LA conversion: this increased from $\sim 65 \%$ up to a quantitative value by increasing the reaction time from 0.5 to $2 \mathrm{~h}$, but it (conversion) remained rather constant in each set of experiments $(\sim 65 \%, \sim 85 \%$, and $>97 \%$ at $0.5,1$, and $2 \mathrm{~h}$, respectively). Remarkably, however, the use of a IL3/Cat ratio below 6 was not practicable because only partial recovery of $\mathrm{Ru} / \mathrm{C}$ catalyst in the IL phase was possible.

Overall, an IL3/Cat ratio around 15 ( $\sim 360 \mathrm{mg}$ of IL3) corresponded to a good compromise between a satisfactory LA conversion and a high reaction rate ( $92 \%$ after $1 \mathrm{~h}$ ) with the full isolation of $\mathrm{Ru} / \mathrm{C}$ in the IL phase. The last condition $(\mathrm{Ru} / \mathrm{C}$ confinement) was mandatory in order to achieve efficient recycle of the catalyst.

Comparison with and without IL. Once the triphasic system was optimized, our next objective was to compare its efficiency to the biphasic aqueous-isooctane system without IL. Accordingly, two sets of hydrogenation/dehydration reactions of LA were conducted. In the first one, conditions 
were those used in Figure 2 and Table 3, except for the fact the no IL was present (blank experiments): in particular, a multiphase mixture of $5 \% \mathrm{Ru} / \mathrm{C}(25 \mathrm{mg} ; \mathrm{Ru}=0.0124$ $\mathrm{mmol})$, a $1.8 \mathrm{M}$ solution of LA in water $(4.4 \mathrm{~mL})$ and $i$-octane ( $4.4 \mathrm{~mL}$ ) was set to react under 35 atm of $\mathrm{H}_{2}$. In the second set, with the same LA/Cat ratio and with the same volumes/ concentrations of aqueous/ $i$-octane ratios, IL3 was added in a IL3/Cat ratio of 23 (576 mg of IL3). In both sets of reactions, the temperature was varied from 30 to $100{ }^{\circ} \mathrm{C}$, and mixtures were analyzed by NMR after $0.5 \mathrm{~h}$. The results are summarized in Figure 4.

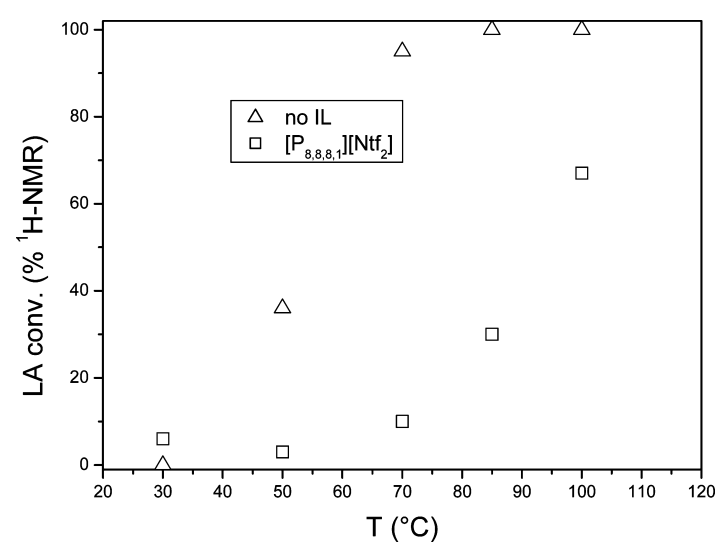

Figure 4. Conversion of LA to GVL in the multiphase system with $5 \%$ $\mathrm{Ru} / \mathrm{C}$ as a function of temperature after $30 \mathrm{~min}:(\Delta)$ without the IL third phase; $(\square)$ with a third phase made by $\left[\mathrm{P}_{8,8,8,1}\right]\left[\mathrm{NTf}_{2}\right]$. Conditions: $p\left[\mathrm{H}_{2}\right]=35$ bar, $\mathrm{Ru} 0.15 \mathrm{~mol} \%$, water $=i$-oct $=8.8$ $\mathrm{mL},\left[\mathrm{P}_{8,8,8,1}\right]\left[\mathrm{NTf}_{2}\right]=576 \mathrm{mg}, 0.87 \mathrm{mmol}$.

At temperatures between 50 and $90{ }^{\circ} \mathrm{C}$, the reaction was faster in the biphasic system without the IL ( $\Delta$, blank tests), but $\mathrm{Ru} / \mathrm{C}$ was always dispersed throughout the final mixture (Figure 1, left), meaning that any recover/recycle of the metal catalyst by phase separation was out of question. The kinetics in the triphase system became competitive at $100{ }^{\circ} \mathrm{C}$ where the conversion of LA went up to $67 \%$; under such conditions, $\mathrm{Ru} /$ $\mathrm{C}$ remained confined in the IL, with clean phase separation. In both sets of experiments, the temperature had no effect on the reaction selectivity, which was always $100 \%$ toward the formation of GVL.

Recycle. Because $\mathrm{Ru} / \mathrm{C}$ was confined in the IL phase of our multiphase system, we set up a very simple protocol for the reuse of the catalyst: under conditions of Figure 3 (black dots, 1 $\mathrm{h}$ ), once the first reaction was complete, the lower aqueous phase containing the product GVL was removed and a fresh aqueous layer containing LA was added. The recycling procedure was repeated eight times using an IL/Cat ratio of 24.0 and verified on a second set of recycles. The results of the first set are illustrated in Figure 5.

Conversion was substantially constant, in the range of 75$80 \%$, over 8 subsequent runs. Selectivity was always $100 \%$ on GVL. Overall, this trend proved one of the major advantages of the procedure: the inverse multiphase LA hydrogenation engineered via IL allowed an efficient recycle of the catalyst hitherto not possible with other methods.

Homogeneous Catalyst: $\mathrm{RuCl}_{3}$. The investigation continued by switching to homogeneous $\mathrm{RuCl}_{3}$ as catalyst for the multiphase reduction/dehydration of LA to GVL. Rationale for using a soluble metal complex was based on previous reports

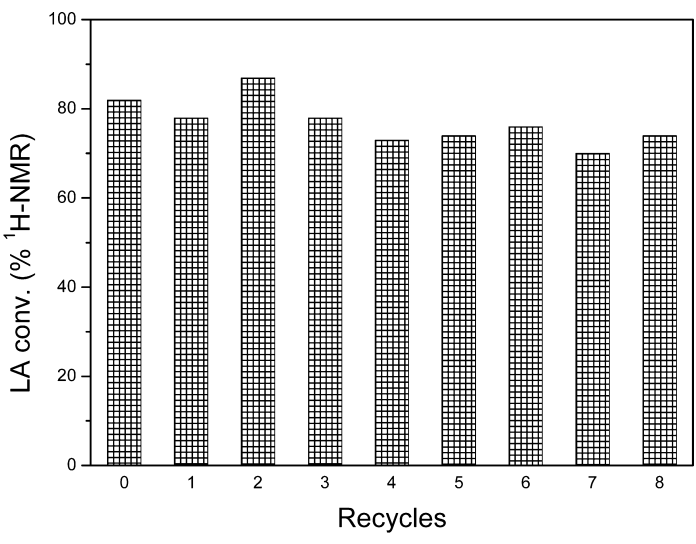

Figure 5. Conversion of LA to GVL: recycling of the $\mathrm{Ru} / \mathrm{C}$ catalyst system. Conditions: $1 \mathrm{~h}, 100{ }^{\circ} \mathrm{C}, p\left[\mathrm{H}_{2}\right]=35$ bar, $\mathrm{Ru} 0.15 \mathrm{~mol} \%(\mathrm{Ru}$ $0.0124 \mathrm{mmol})$, water $=i$-octane $=4.4 \mathrm{~mL},\left[\mathrm{P}_{8,8,8,1}\right]\left[\mathrm{NTf}_{2}\right]=610 \mathrm{mg}$, $0.92 \mathrm{mmol}$.

that showed how this is also an active catalytic species, ${ }^{11-13,24,25}$ and on our knowledge on partitioning of homogeneous metals in IL phases, particularly the immobilization of $\mathrm{RhCl}_{3}$ in $\left[\mathrm{N}_{8,8,8,1}\right][\mathrm{Cl}]$. $^{33}$

As for the case of $\mathrm{Ru} / \mathrm{C}$, a number of multiphase reactions were carried out aimed at segregating the metal catalyst in the IL phase. Among the several ILs that were considered, the choice fell on $\left[\mathrm{N}_{8,8,8,1}\right][\mathrm{Cl}]$ : this salt gave a minor leaching in the water phase (see Table 3), but it also showed a superior capability for the confinement of $\mathrm{Ru}$. Most advantageous conditions were then defined according to the following set: $150{ }^{\circ} \mathrm{C}, 16 \mathrm{~h}, 35 \mathrm{~atm}$ of $\mathrm{H}_{2}, \mathrm{RuCl}_{3}(20 \mathrm{mg}, 0.0765 \mathrm{mmol})$, LA $(810 \mu \mathrm{L}, 7.875 \mathrm{mmol}), \mathrm{H}_{2} \mathrm{O} /$ i-octane $=1: 1(4.4 \mathrm{~mL})$, and a IL/ catalyst ratio $\geq 7$. The results are summarized in Figure 6 . The conversion of LA increased by increasing the IL/catalyst ratio up to 7. Then, further addition of the IL had no effect on conversion, which leveled off to $\sim 65 \%$.

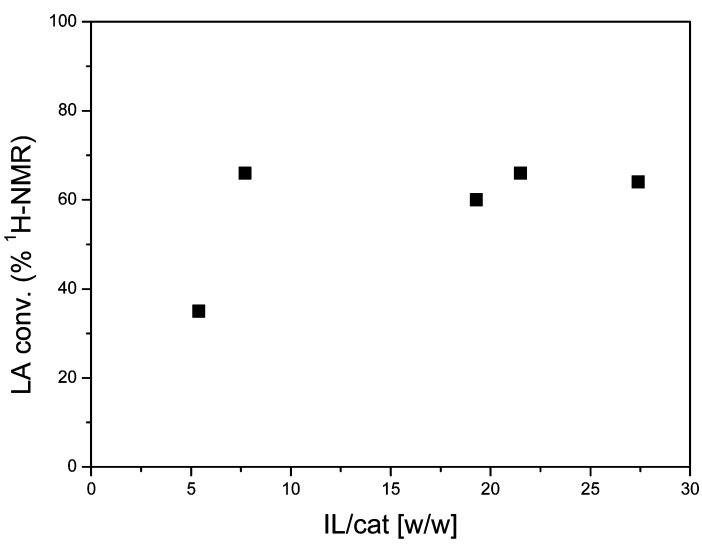

Figure 6. Conversion of LA to GVL as a function of the $\mathrm{IL} / \mathrm{Cat}$ ratio in the $i$-octane-water- $\left[\mathrm{N}_{8,8,8,1}\right][\mathrm{Cl}]$ triphase system with $\mathrm{RuCl}_{3}$ after $16 \mathrm{~h}$. Conditions $150{ }^{\circ} \mathrm{C}, p\left[\mathrm{H}_{2}\right]=35$ bar, $\mathrm{RuCl}_{3}(20 \mathrm{mg}, 0.0765$ $\mathrm{mmol})$, LA $(810 \mu \mathrm{L}, 7.875 \mathrm{mmol}), \mathrm{H}_{2} \mathrm{O}=i$-octane $=4.4 \mathrm{~mL}$.

Notwithstanding that the reaction was not quantitative, a remarkable change of the reacting mixture was observed: although the starting mixture of isooctane, water, and $\left[\mathrm{N}_{8,8,8,1}\right][\mathrm{Cl}]$ with $\mathrm{RuCl}_{3}$ appeared biphasic initially, it became triphasic, however, once subjected for $16 \mathrm{~h}$ to the reaction conditions, as shown in Figure 7. 


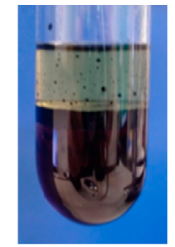

time $=\mathbf{0 ~ h}$

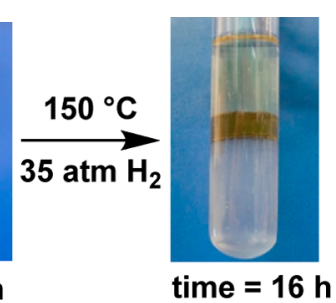

Figure 7. Conversion of LA to GVL with $\mathrm{RuCl}_{3}$ in the multiphase system: formation of the triphase system after $16 \mathrm{~h}$ reaction.

On the basis of our previous experience with homogeneous Pd catalyst precursors that over time formed catalytically active nanoparticles in multiphase systems, ${ }^{34}$ we therefore conducted a number of recycling experiments on the triphasic mixture. These were carried out by the same method described previously (Figure 5): after a first reaction catalyzed by $\mathrm{RuCl}_{3}$, the lower aqueous phase containing the product GVL was removed and a fresh aqueous layer containing LA was added. Rewardingly, just one recycle was sufficient to boost conversion of LA to $99 \%$, with total selectivity toward GVL, as summarized in Figure 8.

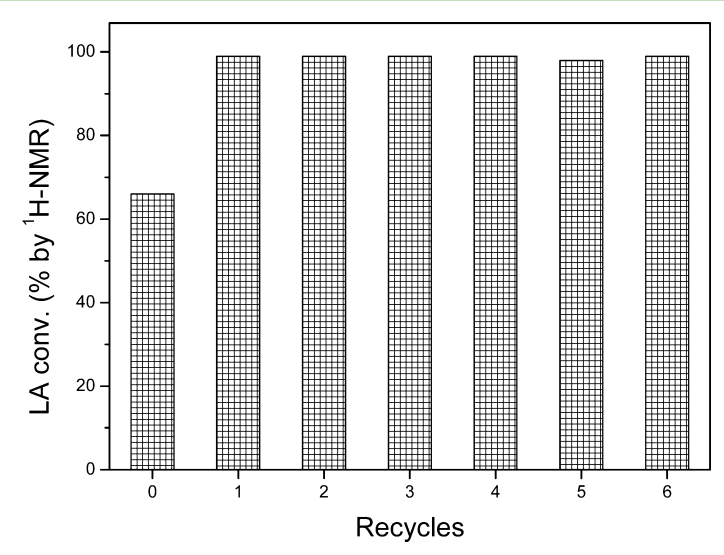

Figure 8. Conversion of LA to GVL: recycling of the $\mathrm{RuCl}_{3}$ catalyst system. Conditions: $16 \mathrm{~h}, 150{ }^{\circ} \mathrm{C}, p\left[\mathrm{H}_{2}\right]=35 \mathrm{bar}, \mathrm{RuCl}_{3}(20 \mathrm{mg}$, $0.0765 \mathrm{mmol} ; \mathrm{Ru}=1.0 \mathrm{~mol} \%), \mathrm{LA}\left(810 \mu \mathrm{L}, 7.875 \mathrm{mmol}, \mathrm{H}_{2} \mathrm{O}=i-\right.$ octane $=4.4 \mathrm{~mL},\left[\mathrm{~N}_{8,8,8,1}\right][\mathrm{Cl}](399 \mathrm{mg}, 0.99 \mathrm{mmol})$.

Both the visual observation of the reaction mixture (Figure 7) and the trend of Figure 8 provided evidence for the modification of $\mathrm{RuCl}_{3}$ into a more active catalytic species. The remarkable increase of the LA conversion from the initial test with $\mathrm{RuCl}_{3}(60 \%)$ and the subsequent experiments of Figure 8 (100\%) suggested that the recycled catalyst might be operating very close to its maximum activity. An analogous behavior was observed by us on previous investigation of $\mathrm{Ru}$ - and $\mathrm{Pd}$ multiphase systems. ${ }^{33,34}$ Further studies of this aspect appeared beyond the scope of the present paper.

Use of Levulinic Acid-Formic Acid mixture. The acidcatalyzed hydrolytic treatment of cellulose is the common route to produce biomass-derived LA. By this method, however, pure LA acid not is obtained but rather aqueous mixtures of LA and formic acid (FA). ${ }^{24}$ This result along with the known capability of FA (and its derivatives) to act as a source of hydrogen, ${ }^{38-40}$ has fueled investigations for intensified processes of upgrading LA to GVL by the use of FA as an in situ hydrogenating agent (Scheme 3). ${ }^{2,24,25}$
Scheme 3. Hydrogenation/Dehydration of LA to GVL Using FA as Hydrogen Source

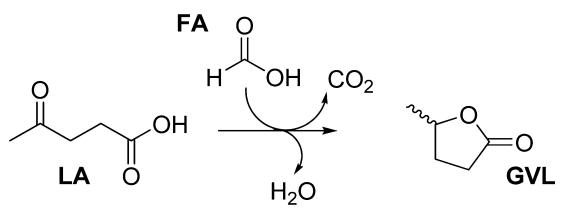

In analogy to these approaches, we decided to explore our inverse multiphase system for FA-promoted hydrogenations of LA. This meant that, with all the other components of the multiphase arrangement being unaltered, the water phase was made up of aqueous solutions of LA/FA. A large set of experiments was conducted using different ratios of both acids and $\mathrm{Ru} / \mathrm{C}$ as catalyst.

Relatively harsh conditions were necessary to exploit the transfer of $\mathrm{H}_{2}$ from FA to LA. In the presence of $5 \% \mathrm{Ru} / \mathrm{C}$ $(0.15 \% \mathrm{~mol}, 0.0124 \mathrm{mmol}$ of $\mathrm{Ru})$, on the plain aqueous LA/FA mixture $(1: 1 \mathrm{~mol} / \mathrm{mol} ; 7.9 \mathrm{mmol}$ of each acid; $4.4 \mathrm{~mL}$ solution), a maximum $18 \%$ of GVL was observed when a temperature as high as $180{ }^{\circ} \mathrm{C}$ was used for $48 \mathrm{~h}$. The triphase system made by adding $i$-octane $(4.4 \mathrm{~mL})$ and $\left[\mathrm{P}_{8,8,8,1}\right]\left[\mathrm{Ntf}_{2}\right]$ (450 mg; IL/Cat $=18$, wt $/ \mathrm{wt})$ inhibited the reaction completely. Although FA could not be used for the reduction of LA under multiphase conditions, we investigated whether a mimic of the LA/FA industrial mixture could be converted to GVL by the addition of $\mathrm{H}_{2}$ to our multiphase system. In analogy to a recent work by Dumesic and co-workers, ${ }^{22}$ a mixture of LA and FA in a 1:1 molar ratio was set to react at $150{ }^{\circ} \mathrm{C}$ under $35 \mathrm{~atm}$ of $\mathrm{H}_{2}$. Selected results and reaction conditions are reported in Table 4.

In the presence of $5 \% \mathrm{Ru} / \mathrm{C}$ and added $\mathrm{H}_{2}$, the reaction of the LA/FA mixture in water proceeded to yield GVL in yields up to $77 \%$ (run 1, $16 \mathrm{~h}$ ); however, the biphasic system formed upon addition of $i$-octane depressed these yields down to $42 \%$ (run 2, $16 \mathrm{~h}$ ), and further addition of $\left[\mathrm{P}_{8,8,8,1}\right]\left[\mathrm{NTf}_{2}\right]$ to give a triphasic system resulted in even lower amounts of GVL (9\%) (run 3), even after a prolonged reaction time ( $32 \mathrm{~h})$. On the basis of literature reports on transfer hydrogenations with FA promoted by a catalytic amounts of amines, ${ }^{41}$ trioctylamine (TOA) was tested in our triphase system made by water $/ i$ octane $/\left[\mathrm{P}_{8,8,8,1}\right]\left[\mathrm{NTf}_{2}\right]$. This reaction reached a $21 \%$ yield (run 4). Analogous experiments carried out in a triphase system made by water/i-octane $/\left[\mathrm{N}_{8,8,8,1}\right][\mathrm{Cl}]$ with added TOA and $\mathrm{RuCl}_{3}$ as the catalyst gave a maximum $13 \%$ conversion of the LA/FA mixture to GVL (run 5).

\section{DISCUSSION}

A first "design and test" phase was required to set up a multiphase system for the conversion of LA to GVL (Scheme 2) with built-in catalyst separation. The objective was 2 -fold: not only the identification of an efficient multiphase catalytic procedure but, even more important, the possibility to confine/ isolate and recycle the (precious) metal catalyst. On the basis of our previous knowledge, ${ }^{30,32-34,42-45}$ we initially focused on triphase systems composed by (i) an organic solvent able to dissolve the LA reagent and GVL product; (ii) an ionic liquid (catalyst-philic) phase able to segregate the metal catalyst; and (iii) an aqueous phase necessary to generate the phase separation. The screening of six readily available organic solvents including hydrocarbons ( $i$-octane, toluene, and cyclohexane), esters (ethyl lactate and acetate), and acetonitrile 
Table 4. Reaction of the LA/FA Mixture to Yield GVL ${ }^{a}$

\begin{tabular}{|c|c|c|c|c|c|}
\hline $\mathrm{H}_{2} \mathrm{O}(\mathrm{mL})$ & $i$-octane $(\mathrm{mL})$ & catalyst & $\mathrm{IL}$ & base $^{b}(\mathrm{TOA} / \mathrm{FA} \mathrm{mol} / \mathrm{mol})$ & LA conversion, ${ }^{c} \%$ (time) \\
\hline 4.4 & 0 & $\mathrm{Ru} / \mathrm{C}$ & & & $77(16 \mathrm{~h})$ \\
\hline 4.4 & 4.4 & $\mathrm{Ru} / \mathrm{C}$ & & & $42(16 \mathrm{~h})$ \\
\hline 4.4 & 4.4 & $\mathrm{Ru} / \mathrm{C}$ & {$\left[\mathrm{P}_{8,8,8,1}\right]\left[\mathrm{NTf}_{2}\right]$} & & $9(32 \mathrm{~h})$ \\
\hline 4.4 & 4.4 & $\mathrm{Ru} / \mathrm{C}$ & {$\left[\mathrm{P}_{8,8,8,1}\right]\left[\mathrm{NTf}_{2}\right]$} & TOA $(10: 31)$ & $21(16 \mathrm{~h})$ \\
\hline 4.4 & 4.4 & $\mathrm{RuCl}_{3}$ & {$\left[\mathrm{~N}_{8,8,8,1}\right][\mathrm{Cl}]$} & TOA $(5: 31)$ & $13(16 \mathrm{~h})$ \\
\hline
\end{tabular}

${ }^{a}$ Conditions: LA $(810 \mu \mathrm{L}, 7.9 \mathrm{mmol})$, FA $(300 \mu \mathrm{L}, 7.9 \mathrm{mmol}), 150{ }^{\circ} \mathrm{C}, p\left[\mathrm{H}_{2}\right]=35$ bar; entries $1-4: \mathrm{Ru} / \mathrm{C}=0.15 \% \mathrm{~mol}(0.0124 \mathrm{mmol}$ of $\mathrm{Ru})$; entries 3-4: $\left[\mathrm{P}_{8,8,8,1}\right]\left[\mathrm{NTf}_{2}\right](450 \mathrm{mg}$, IL/Cat $=18$, wt $/ \mathrm{wt})$; entry 5: $\mathrm{RuCl}_{3}=1 \% \mathrm{~mol}(20 \mathrm{mg} \mathrm{of} \mathrm{Ru}),\left[\mathrm{N}_{8,8,8,1}\right][\mathrm{Cl}](360 \mathrm{mg}, \mathrm{IL} / \mathrm{Cat}=18) .{ }^{b} \mathrm{TOA}=$ trioctyl amine; entries 4 and 5: 2.5 and 1.27 mmol. ${ }^{c}$ Conversions were measured by ${ }^{1} \mathrm{H}$ NMR.

proved that none of them was suitable to our purpose: in the presence of $\left[\mathrm{N}_{8,8,8,1}\right][\mathrm{Cl}]$ as a model IL, some (esters and acetonitrile) were good solvents for reagents and products but also partitioned in the water phase and partially dissolved the IL, whereas some others (hydrocarbons) gave excellent phase separation but were not able to act as solvents.

The original triphase scheme was not effective. Therefore, we decided for a well-separated triphase system made by $i$-octanewater-IL in which the highly polar LA and GVL were dissolved in the aqueous phase and reacted in it, rather than in the organic phase. This kind of solvent system represents an atypical solution for multiphase reactions for which we coined the name inverse multiphase system. It is important to underline that the role of a third-apparently "inactive"phase of $i$-octane is justified precisely by the good phase separation that is able to be induced.

In the presence of $5 \% \mathrm{Ru} / \mathrm{C}$ as a catalyst, a series of experiments allowed optimization of the IL phase, the IL/Cat ratio, and general experimental conditions $(T, P$, time $)$ in order to combine high LA conversion and GVL selectivity with phase separation and acceptable reaction times. These included the triphase system made by $i$-octane-water- $\left[\mathrm{P}_{8,8,8,1}\right]\left[\mathrm{NTf}_{2}\right]$ at $100{ }^{\circ} \mathrm{C}$ with 35 atm $\mathrm{H}_{2}, 1 \mathrm{~h}, \mathrm{IL} / \mathrm{Cat}=14-16(\mathrm{w} / \mathrm{w}), \mathrm{Ru} / \mathrm{C}=$ $0.0124 \mathrm{mmol}(\mathrm{Ru}=0.15 \mathrm{~mol} \%), i$-octane $=4.4 \mathrm{~mL}$, and LA aq. solution $(1.8 \mathrm{M}, 4.4 \mathrm{~mL})$. $\mathrm{Ru} / \mathrm{C}$ was chosen from specific literature data reporting its superior performance for the hydrogenation/dehydration of LA; meanwhile $\left[\mathrm{P}_{8,8,8,1}\right]\left[\mathrm{NTf}_{2}\right]$ was devised for the lipophilic properties of the triflamide counteranion able to avoid any partitioning of such an ionic liquid in the water phase. Also, $\left[\mathrm{P}_{8,8,8,1}\right]\left[\mathrm{NTf}_{2}\right]$ turned out to be an outstanding segregating phase for the metal catalyst.

In view of the objective to design a system that would allow simple recycle of the catalytic phase, these optimized conditions were applied to a series of recycling experiments; the whole process is illustrated by Figure 9. The experiments involved simply removing the aqueous GVL-containing phase once the reaction was complete $(\mathrm{A})$ and replacing it with fresh aqueous LA (B), then resubjecting the mixture to the reaction conditions (C). Up to 8 recycles indicated that the system was stable and reusable.

Catalytic tests made it possible to rule out leaching of metal active species in the water phase, while GC-MS analyses of the organic phase did not show any loss of reagent or product in this phase. Although the reaction in the absence of IL was always faster than in the multiphase system, this limitation was largely offset by the ease with which the catalytic system could be recycled.

For comparison, a recent paper of the same reaction that was focused on optimizing conditions ${ }^{26}$ indicated that, with $\mathrm{Ru} / \mathrm{C}$ as catalyst in water as solvent, at $70{ }^{\circ} \mathrm{C}$ and $30 \mathrm{~atm} \mathrm{H}_{2}$ after $3 \mathrm{~h}$, only $23 \%$ yield of GVL was obtained, whereas at $70^{\circ} \mathrm{C}$ and 5

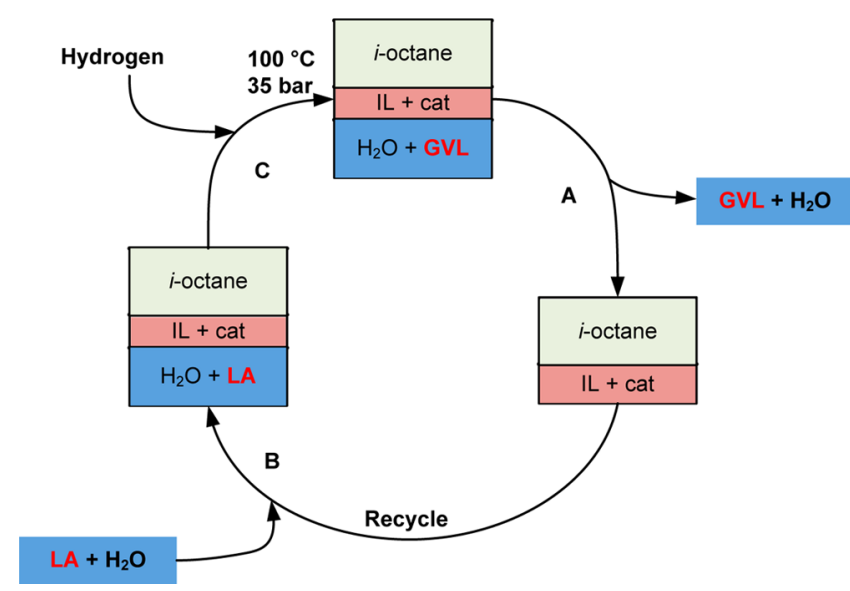

Figure 9. Multiphase conversion of LA to GVL: recycling procedure.

atm of $\mathrm{H}_{2}$, LA conversion did not exceed $13 \%$ unless an acidic cocatalyst was used. As shown in Figure 5, in our case, at the same temperature $\left(70{ }^{\circ} \mathrm{C}\right)$ albeit with $35 \mathrm{~atm} \mathrm{H}_{2}$, conversion reached $>90 \%$ with complete selectivity toward GVL after $4 \mathrm{~h}$. This seems to indicate that the role of the $i$-octane phase is more than just to keep the three phases separate, but that it might also contribute to enhancing or preserving catalyst activity.

It was possible to use homogeneous $\mathrm{RuCl}_{3}$ in place of heterogeneous $\mathrm{Ru} / \mathrm{C}$ in the multiphase system. However, $\mathrm{RuCl}_{3}$ acted as a catalyst precursor rather than a water-soluble metal complex: under $\mathrm{H}_{2}$ pressure, it was rapidly converted into $\mathrm{Ru}$ nanoparticles, which were efficiently confined in the IL phase. Experiments demonstrated that such metal nanoparticles behaved as the active species and they could be easily recovered and recycled. In this case the best operative conditions were so identified: $150{ }^{\circ} \mathrm{C}, 35 \mathrm{~atm} \mathrm{H}_{2}, 16 \mathrm{~h}$, Cat $=\mathrm{RuCl}_{3}(20 \mathrm{mg}$, $0.0765 \mathrm{mmol} ; 1.0 \mathrm{~mol} \%)$, LA $(810 \mu \mathrm{L}, 7875 \mathrm{mmol})$, water $=i$ octane $=4.4 \mathrm{~mL},\left[\mathrm{~N}_{8,8,8,1}\right][\mathrm{Cl}](486 \mathrm{mg})$. The use of $\left[\mathrm{N}_{8,8,8,1}\right][\mathrm{Cl}]$ as the IL phase was based on our previous experience: ${ }^{34}$ this ionic liquid was chosen notwithstanding that it was slightly partitioned in the aqueous phase (Table 3), mainly for its affinity with $\mathrm{RuCl}_{3}$. The performance of such a "homogeneous-multiphase" system was evaluated as a function of the IL/Cat ratio. This showed the following: (i) The LA conversion to GVL could not be further improved above a ratio IL/Cat $(w / w)=7$. In particular, it (conversion) leveled off at around $65 \%$. (ii) $\mathrm{The}_{\mathrm{RuCl}}$ based system appeared less active than the corresponding $\mathrm{Ru} / \mathrm{C}$-based system. However, a peculiar feature of this reaction was that the initial reaction mixture appeared biphasic with the $\mathrm{RuCl}_{3}$ dispersed in the water- $\left[\mathrm{N}_{8,8,8,1}\right][\mathrm{Cl}]$ phase, whereas the final mixture was again perfectly separated in three distinct phases (Figure 7). Deeper 


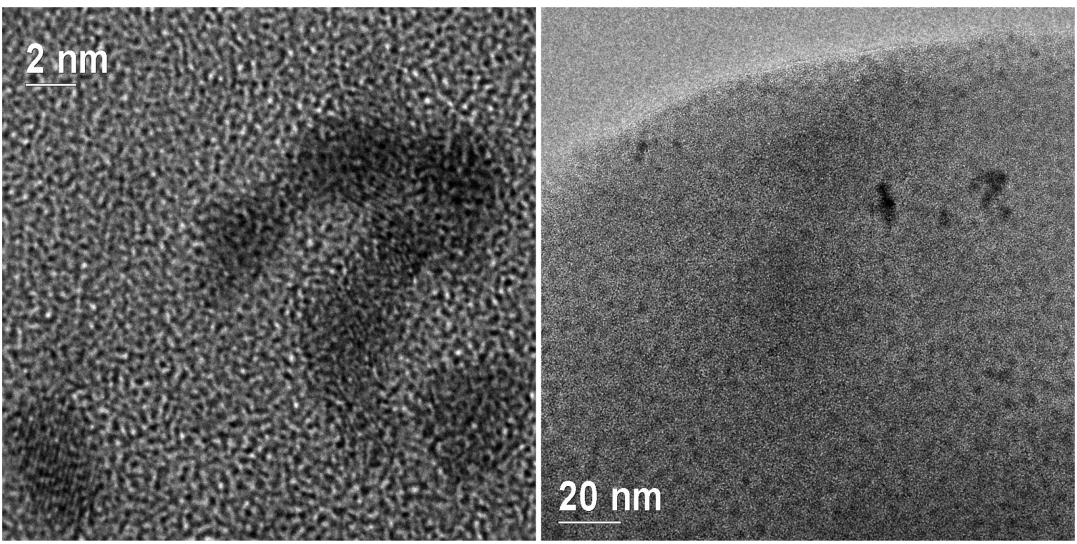

Figure 10. TEM images of Ru nanoparticles formed in the ionic liquid phase under the reaction conditions.

understanding of the reaction as well as positive feedback on the homogeneous system came from the recycling experiments. As shown in Figure 9, when the IL-catalyst ensemble was recovered and reused, the second cycle showed a substantially quantitative conversion of LA to GVL. This indicated that a very active catalytic species could form after an induction period in the system. Moreover, once formed, it was able to promote the reaction for at least 6 cycles without loss of activity. We demonstrated that, at the end of the reaction, the IL phase contained catalytically active $\mathrm{Ru}$ nanoparticles of average size between 2 and $3 \mathrm{~nm}$, as was seen from the TEM pictures in Figure 10. These nanoparticles were stabilized by the presence of the IL and enabled an excellent recycle of the system. Under such conditions, leaching tests for the metal were also carried out as follows: the aqueous layer was removed, fresh LA was added $(810 \mu \mathrm{L}, 7875 \mathrm{mmol})$, and the mixture was stirred for $16 \mathrm{~h}$, at $150{ }^{\circ} \mathrm{C}$ and 35 atm $\mathrm{H}_{2}$. NMR and GC/MS analyses proved that no reaction took place and, therefore, that no residual $\mathrm{Ru}$ was present in water. This is in analogy with the behavior of multiphase LA hydrogenations on $\mathrm{Ru} / \mathrm{C}$.

Finally, we wish to note that, although during the first catalytic run $\left[\mathrm{N}_{8,8,8,1}\right][\mathrm{Cl}]$ was slightly partitioned in the aqueous phase $(2-3 \%)$ as seen earlier (in the Best IL section), gratifyingly once the catalytic $\mathrm{Ru}$ nanoparticles were formed, no trace of $\left[\mathrm{N}_{8,8,8,1}\right][\mathrm{Cl}]$ was detected in water any longer. The reasons for this are still obscure. The experiments demonstrated that our triphase system was not suitable for the LA to GVL conversion using formic acid (FA) as an in situ hydrogen source in the presence of either $\mathrm{Ru} / \mathrm{C}$ or $\mathrm{RuCl}_{3}$, even under additional $\mathrm{H}_{2}$ pressure.

Nonetheless, considering that the output of LA production from cellulose is in any case a mixture of LA and FA, we set out to determine whether this mixture could be treated in our system albeit with the addition of molecular hydrogen. While the aqueous LA/FA mixture could be converted to GVL (77\%) with $\mathrm{Ru} / \mathrm{C}$, addition of $i$-octane and of $\left[\mathrm{P}_{8,8,8,1}\right]\left[\mathrm{NTf}_{2}\right]$ progressively depressed the LA conversions down to $9 \%$ only. Even the addition of an organic base such as trioctylamine to the triphase system slightly improved the conversion to $21 \%$, whereas, under similar conditions, the homogeneous $\mathrm{RuCl}_{3}$ reached a $13 \%$ conversion. These results seemed to indicate that the presence of FA was always detrimental for the catalytic activity of the multiphase system. However, the efficiency of our catalyst system was comparable, if not better, than others recently reported. ${ }^{26}$

\section{CONCLUSIONS}

This investigation demonstrates that multiphase systems formed by the mutual immiscibility of three liquid phases such as water, $i$-octane, and an ionic liquid can be efficient arrangements to run catalytic hydrogenation reactions of LA and, most of all, to simply recover and recycle Ru-based catalysts. Other advantages of multiphase systems are the easy experimental setup and the high versatility that allows the use of both heterogeneous catalysts and homogeneous metal precursors.

The hydrogenation reaction takes place in the water phase, while the metal segregation occurs in the IL. Although the presence of the hydrocarbon solvent ( $i$-octane) appears at first sight inconsequential, it is instead functional to good phase separation for the recovery of products and catalyst, as well as positive with regards to the kinetics of the global reaction.

In all cases, experiments have demonstrated that the architecture of triphase systems preserves the catalytic performance unaltered over several (at least eight) recycles during which the GVL product is easily recovered by phase separation and isolated in yields up to $99 \%$ after each reaction. This represents a major advantage over most procedures reported for the conversion of LA to GVL where the recovery and reuse of the catalyst (especially from water-based matrices) is hardly efficient, if practicable at all.

A limitation of our system has been found in its application to mixtures of LA/FA, meaning that the multiphase procedure cannot be extended to the upgrade of crude LA/FA streams from the hydrolysis of cellulose. Nonetheless, the multiphase method here described in view of the several issues above addressed and the inventive involvement/application of ionic liquid phases represent a genuine approach to design chemical transformation that are intrinsically greener at the outset.

\section{ASSOCIATED CONTENT}

Supporting Information

Synthesis of ionic liquids and NMR spectra of compounds. This material is available free of charge via the Internet at http:// pubs.acs.org.

\section{AUTHOR INFORMATION}

\section{Corresponding Author}

*E-mail: selva@unive.it, alvise@unive.it.

Notes

The authors declare no competing financial interest. 


\section{ACKNOWLEDGMENTS}

The authors gratefully acknowledge dr. Patrizia Canton for TEM analyses and MIUR (Grant "Assegnazione borse aggiuntive Dottorato, es. 2008”) for funding.

\section{REFERENCES}

(1) Werpy, T.; Petersen, G. Top Value Added Chemicals from Biomass; U. S. Department of Energy, Pacific Northwest National Laboratory, National Reneable Energy Laboratory, Office of Biomass Program: Richland, WA, 2004.

(2) Bozell, J. J.; Moens, L.; Elliott, D. C.; Wang, Y.; Neuenscwander, G. G.; Fitzpatrick, S. W.; Bilski, R. J.; Jarnefeld, J. L. Production of levulinic acid and use as a platform chemical for derived products. Resour. Conserv. Recycl. 2000, 28 (3-4), 227-239.

(3) Ragauskas, A. J.; Williams, C. K.; Davison, B. H.; Britovsek, G.; Cairney, J.; Eckert, C. A.; Frederick, W. J.; Hallett, J. P.; Leak, D. J.; Liotta, C. L.; Mielenz, J. R.; Murphy, R.; Templer, R.; Tschaplinski, T. The path forward for biofuels and biomaterials. Science 2006, 311 (5760), 484-489.

(4) Hayes, J.; Ross, J.; Hayes, M. H. B.; Fitzpatrick, S. In Biorefineries: Industrial Processes and Products; Kamm, B., Gruber, P. R., Kamm, M., Eds.; Wiley: Weinheim, Germany, 2005; p 139.

(5) Centi, G.; Lanzafame, P.; Perathoner, S. Analysis of the alternative routes in the catalytic transformation of lignocellulosic materials. Catal. Today 2011, 167 (1), 14-30.

(6) Patel, A. D.; Serrano-Ruiz, J. C.; Dumesic, J. A.; Anex, R. P. Techno-economic analysis of 5-nonanone production from levulinic acid. Chem. Eng. J. 2010, 160 (1), 311-321.

(7) Serrano-Ruiz, J. C.; Wang, D.; Dumesic, J. A. Catalytic upgrading of levulinic acid to 5-nonanone. Green Chem. 2010, 12 (4), 574-577.

(8) Lange, J. P.; Price, R.; Ayoub, P. M.; Louis, J.; Petrus, L.; Clarke, L.; Gosselink, H. Valeric biofuels: A platform of cellulosic transportation fuels. Angew. Chem., Int. Ed. 2010, 49 (26), 4479-4483.

(9) Manzer, L. E. Catalytic synthesis of alpha-methylene-gammavalerolactone: A biomass-derived acrylic monomer. Appl. Catal., A 2004, 272 (1-2), 249-256.

(10) Dodds, D. R.; Gross, R. A. Chemicals from biomass. Science 2007, 318 (5854), 1250-1251.

(11) Mehdi, H.; Fabos, V.; Tuba, R.; Bodor, A.; Mika, L. T.; Horvath, I. T. Integration of homogeneous and heterogeneous catalytic processes for a multi-step conversion of biomass: From sucrose to levulinic acid, gamma-valerolactone, 1,4-pentanediol, 2-methyl-tetrahydrofuran, and alkanes. Top. Catal. 2008, 48 (1-4), 49-54.

(12) Fegyverneki, D.; Orha, L.; Lang, G.; Horvath, I. T. Gammavalerolactone-based solvents. Tetrahedron 2010, 66 (5), 1078-1081.

(13) Horvath, I. T.; Mehdi, H.; Fabos, V.; Boda, L.; Mika, L. T. Gamma-valerolactone-A sustainable liquid for energy and carbonbased chemicals. Green Chem. 2008, 10 (2), 238-242.

(14) Horvath, I. T. Solvents from nature. Green Chem. 2008, 10 (10), $1024-1028$.

(15) Corma, A.; Iborra, S.; Velty, A. Chemical routes for the transformation of biomass into chemicals. Chem. Rev. 2007, 107 (6), 2411-2502.

(16) Schuette, H. A.; Thomas, R. W. Normal valerolactone. III. Its preparation by the catalytic reduction of levulinic acid with hydrogen in the presence of platinum oxide. J. Am. Chem. Soc. 1930, 52, 30103012.

(17) Christian, R. V., Jr.; Brown, H. D.; Hixon, R. M. Derivatives of $\gamma$ valerolactone, 1,4-pentanediol and 1,4-di-( $\beta$-cyanoethoxy)-pentane. $J$. Am. Chem. Soc. 1947, 69, 1961-1963.

(18) Leonard, R. H. Levulinic acid as a chemical basic raw material. J. Ind. Eng. Chem. 1956, 48 (8), 1331-1341.

(19) Smith Broadbent, H.; Campbell, G. C.; Bartley, W. J.; Johnson, J. J. Rhenium and its compounds as hydrogenation catalysts. III. Rhenium heptoxide. J. Org. Chem. 1959, 24, 1847-1854.

(20) Timokhin, B. V.; Baransky, V. A.; Eliseeva, G. D. Levulinic acid in organic synthesis. Usp. Khim. 1999, 68 (1), 80-93.
(21) Heeres, H.; Handana, R.; Chunai, D.; Rasrendra, C. B.; Girisuta, B.; Heeres, H. J. Combined dehydration/(transfer)-hydrogenation of C6-sugars (D-glucose and D-fructose) to gamma-valerolactone using ruthenium catalysts. Green Chem. 2009, 11 (8), 1247-1255.

(22) Serrano-Ruiz, J. C.; Braden, D. J.; West, R. M.; Dumesic, J. A. Conversion of cellulose to hydrocarbon fuels by progressive removal of oxygen. Appl. Catal., B 2010, 100 (1-2), 184-189.

(23) Upare, P. P.; Lee, J. M.; Hwang, D. W.; Halligudi, S. B.; Hwang, Y. K.; Chang, J. S. Selective hydrogenation of levulinic acid to gammavalerolactone over carbon-supported noble metal catalysts. J. Ind. Eng. Chem. 2011, 17 (2), 287-292.

(24) Deng, L.; Li, J.; Lai, D. M.; Fu, Y.; Guo, Q. X. Catalytic conversion of biomass-derived carbohydrates into gamma-valerolactone without using an external H-2 supply. Angew. Chem., Int. Ed. 2009, 48 (35), 6529-6532.

(25) Geilen, F. M. A.; Engendahl, B.; Harwardt, A.; Marquardt, W.; Klankermayer, J.; Leitner, W. Selective and flexible transformation of biomass-derived platform chemicals by a multifunctional catalytic system. Angew. Chem., Int. Ed. 2010, 49 (32), 5510-5514.

(26) Galletti, A. M. R.; Antonetti, C.; De Luise, V.; Martinelli, M. A sustainable process for the production of gamma-valerolactone by hydrogenation of biomass-derived levulinic acid. Green Chem. 2012, 14 (3), 688-694.

(27) Favre, F.; Olivier-Bourbigou, H.; Commereuc, D.; Saussine, L. Hydroformylation of 1-hexene with rhodium in non-aqueous ionic liquids: How to design the solvent and the ligand to the reaction. Chem. Commun. 2001, 15, 1360-1361.

(28) Dupont, J.; Fonseca, G. S.; Umpierre, A. P.; Fichtner, P. F. P.; Teixeira, S. R. Transition-metal nanoparticles in imidazolium ionic liquids: Recycable catalysts for biphasic hydrogenation reactions. J. Am. Chem. Soc. 2002, 124 (16), 4228-4229.

(29) Dyson, P. J.; Geldbach, T. J. Metal Catalysed Reactions in Ionic Liquids; Springer: Berlin, 2005; p 246.

(30) Tundo, P.; Perosa, A. Multiphasic heterogeneous catalysis mediated by catalyst-philic liquid phases. Chem. Soc. Rev. 2007, 36 (3), $532-550$.

(31) Cornils, B.; Herrmann, W. A.; Horvath, I. T.; Leitner, W.; Mecking, S.; Olivier-Bourbigou, H.; Vogt, D. Multiphase Homogeneous Catalysis; Wiley-VCH: Weinheim, Germany, 2005.

(32) Perosa, A.; Tundo, P.; Selva, M.; Zinovyev, S.; Testa, A. Heck reaction catalyzed by $\mathrm{Pd} / \mathrm{C}$, in a triphasic-organic/Aliquat 336/ aqueous-solvent system. Org. Biomol. Chem. 2004, 2 (15), 2249-2252.

(33) Paganelli, S.; Perosa, A.; Selva, M. Triphasic liquid systems for improved separations. Trioctylmethylammonium chloride-immobilised rhodium trichloride: A phosphine-free hydroformylation catalytic system. Adv. Synth. Catal. 2007, 349 (11-12), 1858-1862.

(34) Perosa, A.; Tundo, P.; Selva, M.; Canton, P. Triphasic liquid systems: Generation and segregation of catalytically active $\mathrm{Pd}$ nanoparticles in an ammonium-based catalyst-philic phase. Chem. Commun. 2006, 43, 4480-4482.

(35) Fabris, M.; Lucchini, V.; Noe, M.; Perosa, A.; Selva, M. Ionic liquids made with dimethyl carbonate: Solvents as well as boosted basic catalysts for the Michael reaction. Chem.-Eur. J. 2009, 15 (45), 12273-12282.

(36) Kluson, P.; Cerveny, L. Selective hydrogenation over ruthenium catalysts. Appl. Catal., A 1995, 128 (1), 13-31.

(37) Kim, Y. J.; Varma, R. S. Tetrahaloindate(III)-based ionic liquids in the coupling reaction of carbon dioxide and epoxides to generate cyclic carbonates: H-bonding and mechanistic studies. J. Org. Chem. 2005, 70 (20), 7882-7891.

(38) Blake, P. G.; Davies, H. H.; Jackson, G. E. Dehydration mechanisms in the thermal decomposition of gaseous formic acid. J. Chem. Soc. B 1971, 1923-1925.

(39) Bjerre, A. B.; Soerensen, E. Thermal decomposition of dilute aqueous formic acid solutions. Ind. Eng. Chem. Res. 1992, 31 (6), $1574-1577$.

(40) Saito, K.; Kakumoto, T.; Kuroda, H.; Torii, S.; Imamura, A. Thermal unimolecular decomposition of formic acid. J. Chem. Phys. 1984, 80 (10), 4989-4996. 
(41) Prasad, K.; Jiang, X.; Slade, J. S.; Clemens, J.; Repič, O.; Blacklock, T. J. New trends in palladium-catalyzed transfer hydrogenations using formic acid. Adv. Synth. Catal. 2005, 347 (14), 17691773.

(42) Perosa, A.; Tundo, P.; Zinovyev, S. Mild catalytic multiphase hydrogenolysis of benzyl ethers. Green Chem. 2002, 4 (5), 492-494.

(43) Tundo, P.; Perosa, A.; Zinovyev, S. Modifier effects on Pt/C, $\mathrm{Pd} / \mathrm{C}$, and Raney-Ni catalysts in multiphase catalytic hydrogenation systems. J. Mol. Catal. A: Chem. 2003, 204, 747-754.

(44) Tundo, P.; Perosa, A. The action of onium salts and other modifiers on $\mathrm{Pt} / \mathrm{C}, \mathrm{Pd} / \mathrm{C}$, and Raney-Ni catalysts in the multiphase reduction system. React. Funct. Polym. 2003, 54 (1-3), 95-101.

(45) Zinovyev, S. S.; Perosa, A.; Tundo, P. Liquid-phase and multiphase hydrodehalogenation of halobenzenes over $\mathrm{Pd} / \mathrm{C}$ : Reaction selectivity and inhibition/promotion effects by the quaternary salt. J. Catal. 2004, 226 (1), 9-15. 